\title{
Direct pedicle visualization and disc space orientation as the only guide for lumbar pedicular screw insertion
}

\author{
Hosni Salama
}

\begin{abstract}
Background: Different methods for lumbar pedicular screw insertion have been advocated; however, each technique has its cons and pros. Limited resources for O-arm and navigation in our locality enforced us to use our surgical skills to minimize the need for such advanced modalities.

The aim of the study is to clarify the benefits of the use of free-hand technique using direct visualization of the pedicles and disc space as the only guide for pedicular screw insertion using postoperative CT for evaluation of the accuracy of pedicle screw insertion.

Patients and methods: One hundred forty-four screws were inserted in 32 patients using direct pedicle visualization and disc space orientation as a single intraoperative reference guide. The study was conducted in Zagazig University Hospitals from May, 2014, to June, 2015. CT was done for all patients as a direct postoperative evaluation tool.
\end{abstract}

Results: There were 24 cases of single-level lumbar degenerative spondylolisthesis (96 screws) and eight with double-level degenerative spondylolisthesis DSL (48 screws). One hundred forty-four screws were inserted. Only three out of 144 screws were not purely intrapedicular; superior and lateral violations were not clinically significant.

Conclusions: Direct pedicle visualization with the use of disc space orientation as a reference guide is a good alternative to the most advanced intraoperative monitoring techniques that are more readily available in developed countries.

Trial registration: ClinicalTrials.gov identifier: NCT03327298. Registered 30 October 2017.

Keywords: Pedicle screw, Free hand, Lumbar fixation

\section{Background}

Pedicle screw fixation became a cornerstone in lumbar spine instability surgery since decades. Its ability to engage all three columns of the spine permits application of all the corrective forces distributed equally and safely [1]. Many techniques for insertion of pedicular screws have been described starting from that of Roy-Camille in 1986 [2] who described the pedicular isthmus identification. Others described the free-hand technique [1] depending on the anatomical identification of the pedicle entry point using the transverse process and superior articular process as the main landmarks.

Correspondence: hosni10565@yahoo.com

Zagazig University, Zagazig City, Egypt
Austin et al. [3] noted that the process of screw insertion beyond the entry point is a blind technique which usually depends on the available resources in the operating room along with the surgeon's experience.

The morphological characteristics of the pedicular lamina and roots have been described by Zindrick et al. [4], Saillant et al. [5], and Ebraheim et al. [6].

Despite the recent introduction of more advanced technologies such as O-arm (Medtronic Surgical Navigation Technologies, Louisville, $\mathrm{CO}$ ) and CT-dependent navigation systems [7-11], the postoperative evaluations still show a percentage of pedicle violations with some occasions of neurological compromise.

Computer-assisted image-guided technique has the advantage of giving a real-time two- to three-dimensional 
imaging; many studies noted its superiority on conventional methods [9, 12-14].

Direct pedicle visualization is a more accurate method for detection of pedicular violation than CT-guided techniques [3].

Standard laminectomy is the main step in PLIF for lumbar degenerative spondylolisthesis [15] where the whole lamina with the spinous process and inferior articular facets are removed.

In our study, we evaluated the free-hand technique of pedicular screw insertion depending on direct visualization of the medial and inferior surfaces of the pedicle together with the nerve root and disc space orientation as the only guide without any radiological or neurophysiological aids.

The main motivation for this study is the limited resources for the equipment needed for controlled screw insertion even without the guarantee of the presence of a standard C-Arm being ready at all times.

\section{Methods}

This study was conducted in Zagazig University Hospitals in the period from May 2014 to June 2015 after approval from the Zagazig University Institutional Review Board (Zu-IRB). All patients were subjected to complete history taking, clinical evaluation, and adequate radiological and laboratory investigations.

The radiological studies included plain X-ray lumbosacral spine, anteroposterior, lateral neutral, and lateral dynamic views (lateral with flexion and lateral with extension), MRI lumbosacral spine, sagittal and axial views, and in some cases CT lumbosacral spine with sagittal reconstruction. All these modalities give us a good idea about both soft tissue and bony pathology in the area of interest. Selection of the patients for surgery was based on clinicoradiologic items.

All our cases of pedicular screw insertion were preceded by full laminectomy with discectomy for interbody fusion. In all cases, the medial and inferior aspects of the pedicle are clearly visualized, so selection of the entry point and direct observation of medial and inferior pedicle violation are two main advantages of this technique. On the other hand, after discectomy, the disc space with the two parallel endplates is available for use as a guide for screw craniocaudal angulation.

After the removal of the whole lamina with its inferior articular processes and removal of fibrocartilagenous tissues overlying the exiting roots and removal of the intervertebral disc, the anatomy of the pedicle and its relation to the exiting roots is clearly evident.

Starting pedicular screw insertion, part of the cortical bone at the inferolateral edge of the superior facet is removed. This entry point lies exactly along the transverse plane passing through the middle of the corresponding transverse process.

At the same time, the inferior and medial surfaces of the pedicle along with the exiting nerve root are clearly visualized, so all factors needed for correct pedicle screw insertion are available including the correct entry point, the mediolateral and craniocaudal orientation in addition to the visual protection provided from inside the canal to observe any medial or inferior pedicle violation.

We used to insert a dissector inside the disc space as an additional guide to craniocaudal orientation of the screw which should be parallel to the disc space.

The process of pedicular screw insertion is completed as usual, and the disc space is properly curetted using the suitable shavers, and then, the prepared autologous bone graft is impacted in the disc space. The remaining screws are inserted, and the rods are installed and secured as usual.

The time needed for each screw insertion was calculated.

During the previous steps, neither fluoroscopic guidance nor neuronavigation were used.

After completion of the previous steps, a single lateral and anteroposterior film was used to confirm the correct screw position.

The surgery is completed as usual, and the patient is discharged for follow-up after 2 weeks, during which a complementary CT scan lumbar spine is routinely performed and analyzed for the accuracy of the screw position.

Pedicle violation was assessed whether medial, inferior, lateral, or superior.

\section{Results}

Thirty-two patients, 19 males and 13 females, with age ranging from 24 to 73 years with the mean age 44 years were admitted to this study.

One hundred forty-four screws were placed in the lumbosacral pedicles of 32 patients using our free-hand technique depending on direct visualization of the pedicles, roots, and intervertebral disc (IVD).

All 32 patients were having degenerative spondylolisthesis: 24 of them were single level and 8 were having double level. L5-S1 level was involved in 13 patients as a single level and in another 7 patients as double levels. L4-5 level was involved in 11 patients as a single level and in 7 patients as double levels (7 with L5-S1 and 0 with L3-4). L3-4 as a single level was present in one case. Of these cases, there were 39 levels, 27 of them were first degree and 12 of them were having second degree spondylolisthesis.

Pedicle violation occurred only in three cases: two lateral and one superior. The mean time for each screw insertion was only $3.5 \mathrm{~min}$ (Tables 1,2 , and 3 ). 
Table 1 Distribution of segments involved and pedicles used for fixation

\begin{tabular}{lllll}
\hline $\begin{array}{l}\text { Segment } \\
\text { involved }\end{array}$ & Alone & $\begin{array}{l}\text { With upper } \\
\text { level }\end{array}$ & $\begin{array}{l}\text { With lower } \\
\text { level }\end{array}$ & Screw/pedicle \\
\hline L3-4 & 1 & 0 & 0 & 2/L3-2/L4 \\
L4-5 & 11 & 0 & 7 & 36/L4-36/L5-14/S1 \\
L5-S1 & 13 & 7 & 0 & 26/L5-26/S1 \\
\hline
\end{tabular}

\section{Discussion}

Since the 1940s, vertebral and pedicle screw fixation have been developed and became increasingly popular among spine surgeons [16]. Although there is increasing use of modern imaging modalities as an aid for pedicular screw insertion, we introduce this study to document the validity of free-hand technique alone for accurate screw insertion.

Our motivation for this study was the limited resources of modern techniques used for pedicular screw insertion in our locality, so we turned back to surgical skills alone.

The definition of free-hand technique refers to the surgical technique that uses bone landmarks for screw insertion without the assistance of any imaging intraoperatively [17].

Although most experienced surgeons prefer using the free-hand pedicle screw insertion technique based on anatomic landmarks, this technique has a variable pedicle perforation rate between 1.7 and $54.7 \%$ [18, 19].

The most common reason for the nerve root irritation and injury is breaching of the medial and the inferior cortex of the pedicle.

Assisted methods broadly include functional measures such as intraoperative neural monitoring and anatomic measures such as computed tomography (CT) and fluoro-based and $\mathrm{O}$-arm-based navigation systems [7-11].

Gelalis et al. [17] mentioned that the screws positioned with free-hand technique tend to perforate the cortex medially, whereas the screws placed with CT navigation guidance seem to perforate more often laterally, and he attributed that to the inaccuracy in determining the midline by the navigation technique. Tow et al. [1] founded lateral breach as the most common type in both free hand (62\% of violations) and navigation groups (64.5\%).

Table 2 Pedicles used and numbers of screw for each pedicle

\begin{tabular}{ll}
\hline Pedicle & No. of screws \\
\hline L3 & 2 \\
L4 & 38 \\
L5 & 62 \\
S1 & 40 \\
\hline
\end{tabular}

Table 3 Pedicle violation by postoperative $C T$

\begin{tabular}{lll}
\hline Type of PV & Amount of PV $(\mathrm{mm})$ & Pedicle involved \\
\hline Medial & 0 & 0 \\
Inferior & 0 & 0 \\
Lateral & $<2$ & 2 \\
Superior & $<2$ & 1 \\
\hline
\end{tabular}

CT was used as the preferred method for detection of pedicular screw position postoperatively [20-22] as bony anatomy is best evaluated with CT.

In our study with the use of this technique, only three screws out of 144 (about 0.02) screws were not 100\% intrapedicular; although their violation to the pedicular cortex was less than $2 \mathrm{~mm}$, it was neither medial nor inferior that is because screw insertion under direct vision prevents the occurrence of this.

We think that is one of the advantages of our technique because medial and inferior violations of the pedicle never occurred as we always revise the screw direction if it appears intraoperatively to violate medial or inferior pedicular cortex.

$\mathrm{Xu}$ et al. [23] compared the accuracy of pedicle screw fixation in cadaveric thoracic spine with the use of RoyCamille technique compared to partial laminectomy technique, and he found that the last technique is better regarding accuracy of pedicle screw insertion.

Gertezbein et al., [24], stated that there is a safety zone of $4 \mathrm{~mm}$ medial to the pedicle, $2 \mathrm{~mm}$ extradural and 2 $\mathrm{mm}$ in subarachnoid space medial to the pedicle from T10 to L4.

Our opinion is that this safety zone is not constant in all patients because the pathology present strongly affected the relation between the pedicle and the dura.

In vivo and in vitro studies showed variations of malpositioned pedicular screws in lumbar spine to be 5 to $41 \%$ and from 3 to $55 \%$ in the dorsal spine due to differences in pedicular anatomy between the dorsal and lumbar zones [25-28].

We think that 0.02 pedicle violation (99.98\% accuracy) is one of the best rates in pedicular screw insertion compared to all previous studies, simply because direct visualization permits immediate correction of the screw position intraoperatively without the use of any monitoring modality except the surgeon's eyes.

Previous studies with $100 \%$ accuracy used modern neuronavigation systems with CT like Girardi et al [29] CT navigation (Stealth navigation system, Microsoft Inc., Redmond, Washington) and Carl et al. [30] CT navigation (GE navigational research computer software GE Medical Systems, Milwaukee, WI, USA).

Comparing our results with other studies using the traditional free-hand technique, the results of pedicle screw accuracy varies from 69 to $74 \%$ [24, 31-34]. 
We usually decompress the neural elements before screw insertion, contrarily to many authors who put screws then do decompression like Girardi et al. [29]. The decompress first technique is the secret for good visualization during screw insertion.

Medial pedicle violation more than $4 \mathrm{~mm}$ puts the roots in high risk of injury, and it is agreed between spine surgeons that medial violation less than $2 \mathrm{~mm}$ is safe [35, 36]; although Ebraheim et al. [6] found the distance between the dural sleeve and medial pedicle surface to be only $1.5 \mathrm{~mm}$, Roy-Camille et al. [2] mentioned it to be 2 to $3 \mathrm{~mm}$.

Our intraoperative observation about the distance between the root sleeve and the medial and inferior pedicular surfaces depends mainly on the pathology present. Disc herniation and degree of spondylolisthesis affect the root position in relation to the pedicle.

The main advantages of free-hand technique for pedicle screw insertion are the shorter operative time and avoidance or minimizing radiation exposure to the patient and the surgical team [37].We agree with this opinion because the mean time needed for screw insertion was $3.5 \mathrm{~min}$ and we use only one fluoroscopic view after completion of all screw insertions, while it was $6.6 \mathrm{~min}$ (3.3 to $12.5 \mathrm{~min}$ ) with the use of CT-guided navigation by Girardi et al. [29].

We routinely decompress the roots first by removal of any offending tissues either bony or soft tissues before insertion of the screws.

According to many previous studies, there is difficulty in assessing correct pedicle screw position with the use of conventional roentgenography [38-40].

Titanium screws cause less artifact in CT and MRI; all our screws were titanium so screw artifact was very minimal.

\section{Conclusions}

Direct pedicle visualization with the use of disc space orientation as reference guide is a good alternative to the most advanced intraoperative monitoring techniques in developing countries.

\section{Funding}

The research has no external funding.

\section{Availability of data and materials}

Please contact author for data requests.

\section{Author's contributions}

The single author of this article was responsible for performing the surgery, data collection and analysis, and writing of the manuscript. The author read and approved the final manuscript.

\section{Ethics approval and consent to participate}

This study was approved by the Zagazig University Institutional Review Board Zu-IRB at 24 March 2014. Written consent from all patients was taken before surgery.

\section{Competing interests}

The author declares no competing interests.

\section{Publisher's Note}

Springer Nature remains neutral with regard to jurisdictional claims in published maps and institutional affiliations.

Received: 31 July 2017 Accepted: 11 November 2017

Published online: 02 July 2018

\section{References}

1. Tow BPB, Yue WM, Srivastava A, Lai JM, Guo CM, Peng BCW, et al. Does navigation improve accuracy of placement of pedicle screws in single-level lumbar degenerative spondylolisthesis?: a comparison between free-hand and three-dimensional O-arm navigation techniques. Clin Spine Surg. 2015; 28(8):E472-7.

2. Roy-Camille R, Saillant G, Mazel C. Internal fixation of the lumbar spine with pedicle screw plating. Clin Orthop Relat Res. 1986;203:7-17.

3. Austin MS, Vaccaro AR, Brislin B, Nachwalter R, Hilibrand AS, Albert TJ. Image-guided spine surgery: a cadaver study comparing conventional open laminoforaminotomy and two image-guided techniques for pedicle screw placement in posterolateral fusion and nonfusion models. Spine. 2002; 27(22):2503-8.

4. Zindrick MR, Wiltse LL, Doornik A, Widell EH, Knight GW, Patwardhan AG, Fields BT. Analysis of the morphometric characteristics of the thoracic and lumbar pedicles. Spine. 1987;12(2):160-6.

5. Saillant G. Anatomical study of the vertebral pedicles. Surgical application. Rev Chir Orthop Reparatrice Appar Mot. 1976;62(2):151-60.

6. Ebraheim NA, Xu R, Darwich M, Yeasting RA. Anatomic relations between the lumbar pedicle and the adjacent neural structures. Spine. 1997;22(20): 2338-41.

7. Fu TS, Chen $L H$, Wong CB, et al. Computer-assisted fluoroscopic navigation of pedicle screw insertion: an in vivo feasibility study. Acta Orthop Scand. 2004;75:730-5.

8. Holly LT, Foley KT. Image guidance in spine surgery. Orthop Clin North Am. 38:451-461, abstract viii. 2007.

9. Amiot LP, Lang K, Putzier M, Zippel H, Labelle $H$. Comparative results between conventional and computer-assisted pedicle screw installation in the thoracic, lumbar, and sacral spine. Spine. 2000;25(5):606-14.

10. Holly LT, Foley KT. Three-dimensional fluoroscopy-guided percutaneous thoracolumbar pedicle screw placement. Technical note. J Neurosurg. 2003; 99(suppl):324-9.

11. Rajan W, Kamath V, Shetty AP, Rajasekaran S. Iso-C3D navigation assisted pedicle screw placement in deformities of the cervical and thoracic spine. Indian J Orthop. 2010;44(2):163.

12. Cinotti G, Gumina S, Ripani M, Postacchini F. Pedicle instrumentation in the thoracic spine: a morphometric and cadaveric study for placement of screws. Spine. 1999:24(2):114-9.

13. Glossop ND, Hu RW, Randle JA. Computer-aided pedicle screw placement using frameless stereotaxis. Spine. 1996;21:2026-34.

14. Merloz P, Tonetti J, Pittet L, Coulomb M, Lavallee S, Sautot P. Pedicle screw placement using image guided techniques. Clin Orthop Relat Res. 1998;354: 39-48.

15. Guo S, Sun J, Tang G. Clinical study of bilateral decompression via vertebral lamina fenestration for lumbar interbody fusion in the treatment of lower lumbar instability. Exp Ther Med. 2013;5(3):922-6.

16. Kabins MB, Weinstein JN. The history of vertebral screw and pedicle screw fixation. lowa Orthop J. 1991;11:127-36.

17. Gelalis ID, Paschos NK, Pakos EE, Politis AN, Arnaoutoglou CM, Karageorgos AC, et al. Accuracy of pedicle screw placement: a systematic review of prospective in vivo studies comparing free hand, fluoroscopy guidance and navigation techniques. Eur Spine J. 2012;21 (2):247-55.

18. Parker SL, McGirt MJ, Farber SH, Amin AG, Rick AM, Suk I, et al. Accuracy of free-hand pedicle screws in the thoracic and lumbar spine: analysis of 6816 consecutive screws. Neurosurgery. 2011;68(1):170-8.

19. Sedory DM, Crawford JJ, Topp RF. The reliability of the ball-tipped probe for detecting pedicle screw tract violations prior to instrumenting the thoracic and lumbar spine. Spine. 2011;36:E447-53.

20. Farber GL, Place HM, Mazur RA, Jones CDE, Damiano TR. Accuracy of pedicle screw placement in lumbar fusions by plain radiographs and computed tomography. Spine. 1995;13:1494-9. 
21. Liljenqvist UR, Halm HFH, Link TM. Pedicle screw instrumentation of the thoracic spine idiopathic scoliosis. Spine. 1997;19:2239-45.

22. Yoo JU, Ghanayem A, Petersilge C, Lewin J. Accuracy of using computed tomography to identify pedicle screw placement in cadaveric human lumbar spine. Spine. 1997;22:2668-71.

23. Xu R, Ebraheim NA, Ou Y, Yeasting RA. Anatomic considerations of pedicle screw placement in the thoracic spine: Roy-Camille technique versus openlamina technique. Spine. 1998;23(9):1065-8.

24. Gertzbein SD, Robbins SE. Accuracy of pedicular screw placement in vivo. Spine. 1990;15(1):11-4.

25. Castro WH, Halm H, Jerosch J, Malms J, Steinbeck J, Blasius S. Accuracy of pedicle screw placement in lumbar vertebrae. Spine. 1996;21(11):1320-4.

26. Esses SI, Sachs BL, Dreyzin V. Complications associated with the technique of pedicle screw fixation a selected survey of ABS members. Spine. 1993; 18(15):2231-9.

27. Schwarzenbach O, Berlemann U, Jost B, Visarius H, Arm E, Langlotz F, Nolte LP, Ozdoba C. Accuracy of computer-assisted pedicle screw placement. An in vivo computed tomography analysis. Spine. 1997;22:452-8.

28. Welch WC, Subach BR, Pollack IF, Jacobs GB. Frameless stereotactic guidance for surgery of the upper cervical spine. Neurosurgery. 1997;40: 958-63.

29. Girardi FP, Cammisa FP, Sandhu HS, Alvarez L. The placement of lumbar pedicle screws using computerised stereotactic guidance. J Bone Joint Surg Br. 1999;81(5):825-9.

30. Carl AL, Khanuja HS, Gatto CA, Matsumoto M, Schenck J, Rohling K, et al. In vivo pedicle screw placement: image-guided virtual vision. Clin Spine Surg. 2000;13(3):225-9.

31. Modi H, Suh SW, Song HR, Yang JH. Accuracy of thoracic pedicle screw placement in scoliosis using the ideal pedicle entry point during the freehand technique. Int Orthop. 2009;33(2):469-75.

32. Karapinar L, Erel N, Ozturk H, Altay T, Kaya A. Pedicle screw placement with a free hand technique in thoracolumbar spine: is it safe? Clin Spine Surg. 2008;21(1):63-7.

33. Laine T, Schlenzka D, Mäkitalo K, Tallroth K, Nolte LP, Visarius H. Improved accuracy of pedicle screw insertion with computer-assisted surgery: a prospective clinical trial of 30 patients. Spine. 1997;22(11):1254-8.

34. Sim E. Location of transpedicular screws for fixation of the lower thoracic and lumbar spine: computed tomography of 45 fracture cases. Acta Orthop Scand. 1993;64(1):28-32.

35. Mirza SK, Wiggins GC, Kuntz Iv C, York JE, Bellabarba C, Knonodi MA, et al. Accuracy of thoracic vertebral body screw placement using standard fluoroscopy, fluoroscopic image guidance, and computed tomographic image guidance: a cadaver study. Spine. 2003;28(4):402-13.

36. Fisher CG, Sahajpal V, Keynan O, Boyd M, Graeb D, Bailey C, et al. Accuracy and safety of pedicle screw fixation in thoracic spine trauma. J Neurosurg Spine. 2006;5(6):520-6.

37. Crostelli M, Mazza O, Mariani M. Free-hand pedicle screws insertion technique in the treatment of 120 consecutive scoliosis cases operated without use of intraoperative neurophysiological monitoring. Eur Spine J. 2012:21:43-9.

38. Farber GL, Place HM, Mazur RA, Jones CDE, Damiano TR. Accuracy of pedicle screw placement in lumbar fusions by plain radiographs and computed tomography. Spine. 1995;13:1494-9.

39. Weinstein JN, Spratt KF, Spengler D, Brick C, Reid S. Spinal pedicle fixation: reliability and validity of roentgenogram-based assessment and surgical factors on successful screw placement. Spine. 1988;9:1012-8.

40. Whitecloud TS, Skalley T, Cook SD, Morgan EL. Roentgenographic measurement of pedicle screw penetration. Clin Orthop. 1989;245:57-68.

\section{Submit your manuscript to a SpringerOpen ${ }^{\circ}$ journal and benefit from:}

- Convenient online submission

- Rigorous peer review

- Open access: articles freely available online

- High visibility within the field

- Retaining the copyright to your article

Submit your next manuscript at $\gg$ springeropen.com 